Article

\title{
When Culture Materializes: Societal Dynamics in Resilience of Social-Ecological Systems in the Case of Conch Management on Abaco, The Bahamas
}

\author{
Lars Bomhauer-Beins *, Corinna de Guttry and Beate M. W. Ratter \\ Institute of Geography, Hamburg University, 20146 Hamburg, Germany; \\ corinna.de.guttry@uni-hamburg.de (C.d.G.); beate.ratter@uni-hamburg.de (B.M.W.R.) \\ * Correspondence: lars.bomhauer-beins@uni-hamburg.de
}

Received: 30 December 2018; Accepted: 14 February 2019; Published: 19 February 2019

check for updates

\begin{abstract}
The concept of resilience has greatly contributed to the scientific discussion on human-nature interactions by analysing the dynamics, relationships and feedbacks between society and the natural environment at different levels. In this paper, we analyse how culture and societal dynamics influence those connections and, at the same time, have the potential to eventually hinder or foster social-ecological resilience. In order to do so, we take the example of a natural element which is also a cultural icon: the Conch (pronounced ' $k o n k$ '). Conch is a marine mollusc with significant social and cultural value for the islands' society of The Bahamas. In the last decade, a decline in several Conch stocks has been documented, calling for an urgent sustainable management strategy. Nevertheless, only little efforts are happening. This case study offers an innovative understanding of resilience by introducing an aspect which is too often overseen: the role of culture in shaping social-ecological resilience. In this case study, the role of culture proved to be crucial as the cultural significance and embeddedness of Conch has made the management process challenging. But at the same time, culture can be used as a positive impulse towards adaptive management and as a starting point for sustainability. When culture materializes, it affects not only societal dynamics but also the vulnerability and the resilience process of the entire social-ecological system.
\end{abstract}

Keywords: Cultural resilience; social-ecological systems (SES); adaptive cycle; Conch management; Bahamas

\section{Introduction}

Understanding social-ecological systems and their resilience is a challenge that forces researchers, decision makers and society to think at multiple scales and to be at ease with concepts such as complexity, nonlinearity, path dependency, uncertainty and change. This challenge cannot be ignored as we are faced with external and internal stressors and shocks such as natural disasters, climate change and resources depletion. When those changes occur, individuals and communities need to find a resilient path in an intricate labyrinth of different types of knowledge, clashing interests and world views, a dependency on routines or patterns of behaviours of the past, divergent visions and ideas of future as well as unexpected responses from the ecosystem.

As scientists, we are left with the difficult task of analysing resilience in a way that takes into consideration both the ecological and the social dimensions of a system, that constructively copes with its nonlinear dynamic nature and that explicitly reflects upon its normative assumptions. In this paper, we embrace this conceptual and empirical challenge by investigating the case of resource management of the marine gastropod Conch in The Bahamas. Our focus lies on the societal dynamics in the management process to reveal how cultural aspects can hinder or foster social-ecological 
resilience. By doing so, we position ourselves in the current debate on social-ecological resilience by understanding resilience as an ongoing process influenced by a variety of social agents acting and interacting at different levels and by recognizing its nonlinear dynamic nature and its profound cultural embeddedness.

\section{Social-Ecological Resilience}

The concept of resilience is-after almost five decades from its first appearance-increasingly manifold and controversial. Sceptics perceive resilience to be a slippery concept, while for the more optimistically minded, it is a concept that allows great interpretive flexibility. On one side, supporters highlight the crucial contribution of resilience theory for system thinking [1] as well as for creating space and stimulating interdisciplinary work [2,3], empirically challenged by [4]. On the other side, resilience has raised a number of critiques in terms of its normative underpinnings [5,6], missing link with culture [7], uncritical approach to equity and fairness and its inherent vagueness [8].

The discussion on resilience became even more convoluted and animated since the concept of resilience-originally based on ecological systems $[9,10]$ - has been broadened and applied to social-ecological systems (SES). This integration started in the late 1990s, with the work of Folke, Berkes and Costanza, among others. After almost three decades of conceptual and empirical contributions from different disciplines, SES resilience is now a well-established branch within the field of resilience thinking.

Despite a wide variety of conceptualizations of SES resilience, three main aspects can be identified across literature: I) the interrelatedness of the ecological and the social system, II) the complexity and nonlinearity of SES and III) its multiple temporal and spatial scale [1,11]. At the basis of these three aspects lies the major contribution of the concept: shifting from an understanding of resilience as stable and linear to nonlinear and dynamic, where change is continuous and happening at multiple scales [12] (hence the term "evolutionary resilience").

The integration of social to ecological system thinking as well as the shift from a static to a dynamic understanding of resilience have not been smooth processes. In fact, much of the conceptual debate on SES resilience is still characterized by a tension between its roots in ecology and an apparent desire to detach from it methodologically and epistemologically. In the best cases, this tension has been productively used and elaborated in interdisciplinary work, making research on SES standout for employing resilience "as a bridging concept and facilitate a discussion of dynamics of complex systems within varied contexts" [4]. In other cases, this tension has led to hesitation with regards to the adequacy of the application of the concept of resilience to social systems and to a call for critical examination and further theoretical development [13].

This paper contributes to the current discussion [14] by shedding light on the roles of societal dynamics and culture in social-ecological resilience. We take up the requirement of a cultural perspective to reveal and understand the interdependency and the dynamics of different components of social and ecological systems across scales. By addressing this aspect, we react to both the call on further research on "the interplay among diverse framings, discourses and values" [15] and to the urgency of a critical approach that reveals the implications of resilience in terms of power dynamics and types of knowledge taken into account [8].

In the following, the societal dynamics, culture, their relationship and their role for understanding social-ecological resilience will be examined in more detail.

\section{Integrating Culture in Resilience Thinking}

Before discussing in detail how culture can shape the resilience of a SES, one important question must be addressed: Why culture? The answer is that the importance of culture begins with the integration of the "social" with the "ecological". As nicely stated by Davidson (2010: 1142), "Social systems are unique in that the tendencies toward complexity, and the responses of individual organisms to those levels of complexity, are defined not solely by structural variables but by agency." [13]. These characteristics 
of social systems imply that when analysing resilience at an SES level, we need to move away from a focus on structural complexity towards behavioural complexity and cross-scale feedback processes and relations $[13,16,17]$. In other words, to understand adaptive processes in an SES, it is not sufficient to look at its different components: it is crucial to analyse the nonlinear dynamics and behaviour among them. The assumption behind this is that the adaptive capacity of a system is not a preexisting or superimposed trait. Rather, it is the emergence of interdependent interactions between people, places, values and knowledge. Those dynamics and interactions are embedded in a cultural context: a physical space where past experiences, routines, values, world views and visions of the future and pathways intermingle. In this paper, these relationships are explicitly emphasized by using both the term social dynamics as an empirical device and the concept of culture with broader, theoretical connotations.

This cultural approach to resilience has been previously advocated by Cote and Nightingale (2012: 484), who argue that heterogeneous adaptive processes "must be understood through the recursive relationship between knowledge, agency and context as mediated by culture and history" [16]. In parallel with our arguments, the two authors see in the cultural approach an opportunity to address normative tensions that characterise current debates on social-ecological resilience and in particular to foment reflections upon the question of "resilience for whom?".

The focus on culture and on societal dynamics in SES's resilience has remained mainly conceptual—with few exceptions. For example, Lade et al. (2015) used a generalized modelling approach to analyse the role of policy decisions and societal dynamics in the collapse of Baltic cod fisheries [18]. Winter et al. (2018) incorporated the keystone concept into the SES theory and have identified taro cultivation as the biocultural element that can be considered the keystone component of the Hawaiian SES [14]. In our paper, we add to this body of literature by supporting our theoretical claims with empirical observations [18]. In fact, to reveal the role of societal dynamics and more broadly of culture in SES's resilience, we will illustrate the case of Conch management on The Bahamas. Conch is a marine mollusc and a cultural entity full of history, stories and symbolic meanings. Because of this, the divergent interests, perceptions and visions on Conch management are extremely variegated and are the result of conflicting world views, power relations, past routines and ecological vulnerability. The case study of Conch management on The Bahamas not only is of great interest for its cultural embeddedness but also offers the possibility to understand the role of culture in a less deterministic and positivist way. Different cultural norms and practices that coexist in an SES can translate into divergent positions on how to move forward with adaptation. In such an intricate situation, the existence of culture and of societal dynamics per se does not guarantee enhanced resilience. As cultural routines are perpetuated, the potential of change and response diversity can decrease, reducing the space for innovation and learning. The problem exacerbates across time and across scales leading to different levels of lock-in situation, where the resistance against change is reinforced and opportunities for adaptive pathways decrease. In this situation, the path-dependent development of a system is stuck and rigid and can only be overcome by external stressors or a radical change (transformation) of the system.

The aim of the paper is, based on the Conch case study, to bring forward an approach to SES's resilience which is founded on culture and societal dynamics. Through this approach, we shed light on the processes that bring different agents of the system to adapt (or not) to changes through interactions and feedbacks among them and with the ecological system. After setting out the mixed methods employed, we discuss the ecological, economic and cultural dimension of Conch in the case study site as well as their (in)direct impacts on the current management process. We emphasize the role of societal dynamics in the resilience of Conch management by analysing the current adaptive capacity of the social system and exploring the potential adaptive pathways based on cultural context and observed societal dynamics. We will close with a discussion of the practical implications of our findings and explicitly reflect upon the contributions of a cultural approach to the body of knowledge on SES's resilience. 


\section{Methodology}

In order to investigate the nonlinear system dynamics and interactions in the Bahamian Conch management process, we applied a mixed method approach of qualitative and quantitative methods, including semi-structured interviews, a semi-standardised population survey, observations and field notes. An empirical data collection phase was carried out from May to July 2017 in Abaco and New Providence. Semi-structured interviews were used to gain a comprehensive view of the current management process, including patterns of relationships, interests, perceptions, behaviours and positions of power. Key stakeholders whose actions and behaviour have a direct influence on the Bahamian Conch management, such as representatives from governmental bodies, non-governmental organisations, associations or interest groups and fishermen, were interviewed. All 17 interviews were anonymised, transcribed and encoded (depicted in text with code I). A semi-standardised population survey with 111 islanders was carried out in nine communities (Islanders were interviewed in the communities of Cherokee Sound, Cooper's Town, Fox Town, Great Guana Cay, Green Turtle Cay, Hope Town, Man-O-War Cay, Marsh Harbour and Sandy Point), scattered across Abaco Island (see Figure 1), and representing the heterogeneity and diversity of the Abaconian society. The population survey with, for the most part, open questions focused on the islander's perspective on the Conch issue (code AS). Interviewees were asked about their perspectives, behaviour, awareness, values, actions, human-nature interactions as well as consumption. Observations served to gain a better understanding of how the Abaconians deal with the marine resource in their everyday life. Both observations and informal talks were directly written down in the form of field notes.

\section{A SES Perspective on Conch in The Bahamas}

In order to understand human-nature interactions, we take a resilience perspective on Conch management in The Bahamas. Abaco, in this case, is understood as a SES and analysed in its interactions, feedbacks and dynamics at different levels and spatiotemporal scales. First, we describe briefly the geographical context of the Bahamian island Abaco. After this, we expose the ecological system with a specific focus on Conch and its dynamics and role within the marine ecosystem. Then, we turn our attention to the social system analysing the cross-scale human-nature interactions between individuals, society and Conch from both an economic and cultural perspective. We conclude with an analysis of the interactions and feedbacks of the ecological and social system by illustrating the current Conch management process in response to the nonlinear social-ecological dynamics previously described.

\subsection{The Big Fishing Island Abaco}

More accurately speaking, Abaco is a chain of islands consisting of two main islands and several offshore cays as part of the small-island archipelago state of The Bahamas. Abaco lies on the Little Bahama Bank and is located around 100 kilometres north of the political, economic and administrative capital Nassau on New Providence and around 300 kilometres away from the east coast of Florida, United States. Abaco's economic centre is the island community of Marsh Harbour with 4386 inhabitants (from the year 2010, of a total population of 17,224 islanders) (see Figure 1). Historically, Abaco was a relatively remote Bahamian Out Island until the 20th century primarily due to its geographical and relational distance to the capital Nassau, New Providence. Even today, many Abaconians feel independent and far away from the political influence of the central government. Over the centuries, since the permanent resettlement of Abaco by American loyalists and their slaves in 1783, the Bahamian waters and its marine resources have always been an essential livelihood for the islanders, especially during difficult economic times. Today, tourism is, similarly to the case of many other islands of the Bahamian archipelago, the backbone of Abaco's economy. Its development is greatly influenced by external drivers, such as international investors and second-home owners, both almost entirely from the United States. Along with the dominance of tourism-mainly focused on 
fishing, boating and sailing — the local fisheries industry plays an important role in terms of staple food supply and employment. Abaco is one of the big fishing societies with around 800 local fishermen. It is estimated that in the traditional fishing communities, such as Fox Town, Grand Cay, Moore's Island and Sandy Point, around 80 percent of the people are directly or indirectly involved in the local fishery sector.

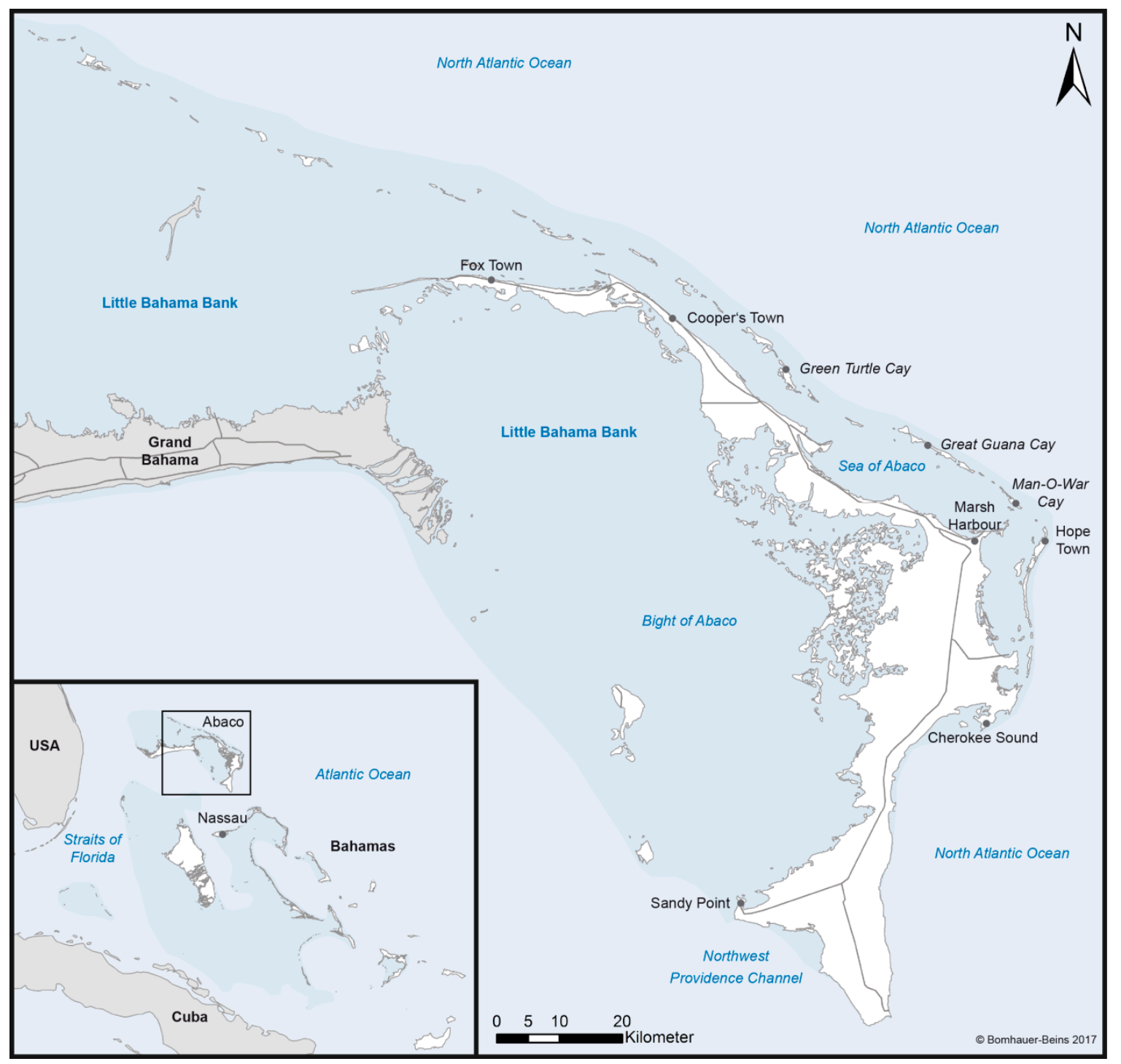

Figure 1. Abaco and the locations of the semi-standardised population survey.

\subsection{Conch from an Ecological System Perspective}

The marine gastropod Queen Conch (Lobatus gigas, formerly known as Strombus gigas) is living across the Wider Caribbean Region, including The Bahamas. Anatomically, the mollusc consists of a solid muscle, a muscle foot, two prolonged feelers with eyes, tentacles and a characteristic pink shimmering shell (see Figure 2).

Its natural habitats are sea grass beds in shallow waters up to thirty metres and coral reefs [19]. As an herbivore, it feeds primarily on seaweed and various types of algae [20]. The life cycle is up to thirty years. Based on international research on Conch, there are minor regional differences with regards to the spawning season, growth period and sexual majority that might have implications for resource management. For The Bahamas, between April and October, the female Conch lay several thousand eggs [21]. After three to four years, the Conch reaches their sexual maturity. At this stage 
of life, they begin to develop their characteristic flared lip that defines them as an adult [20]. Conch plays a crucial role in marine ecosystem dynamics, not the least through its function within the food chain. In fact, natural predators of Conch are turtles, crabs, stingrays, lobster, sharks and other sea snails. As an herbivore, Conch has a direct influence on benthic macro fauna communities.

Some biological characteristics, in particular its slow movement, a tendency towards aggregation and living in shallow waters, make it very easy to catch Conch. "You can't dive down and catch a lobster by your hand. He is gonna run. You can't go and catch a stone crab because he will bite you and he will run. You can't grab any fish because they gonna run. The Queen Conch is the only one that can't run from you." (I6). These aspects coupled with a relatively long period of growth of up to five years and a late sexual maturity are key factors of vulnerability related to the phenomenon of overfishing. Recent studies have shown that the Bahamian Conch stocks are overfished and that some primarily Conch fishing grounds (e.g., around Abaco) are partly on the verge of collapse [22,23]. A long-term study by Stoner et al. (2018: 18) pointed out that "[f]ishery for queen conch might last only another 10 or 15 years unless significant measures are taken to reduce fishing mortality" [24]. According to Stoner and Ray-Culp (2000) the tipping point is at least 50 Adult Conch per hectare [25]. Following resilience thinking, the impact of the ecological collapse of Conch stocks would not be circumscribed to the ecological system: it will also initiate negative feedback effects within the social system and its subsystems.

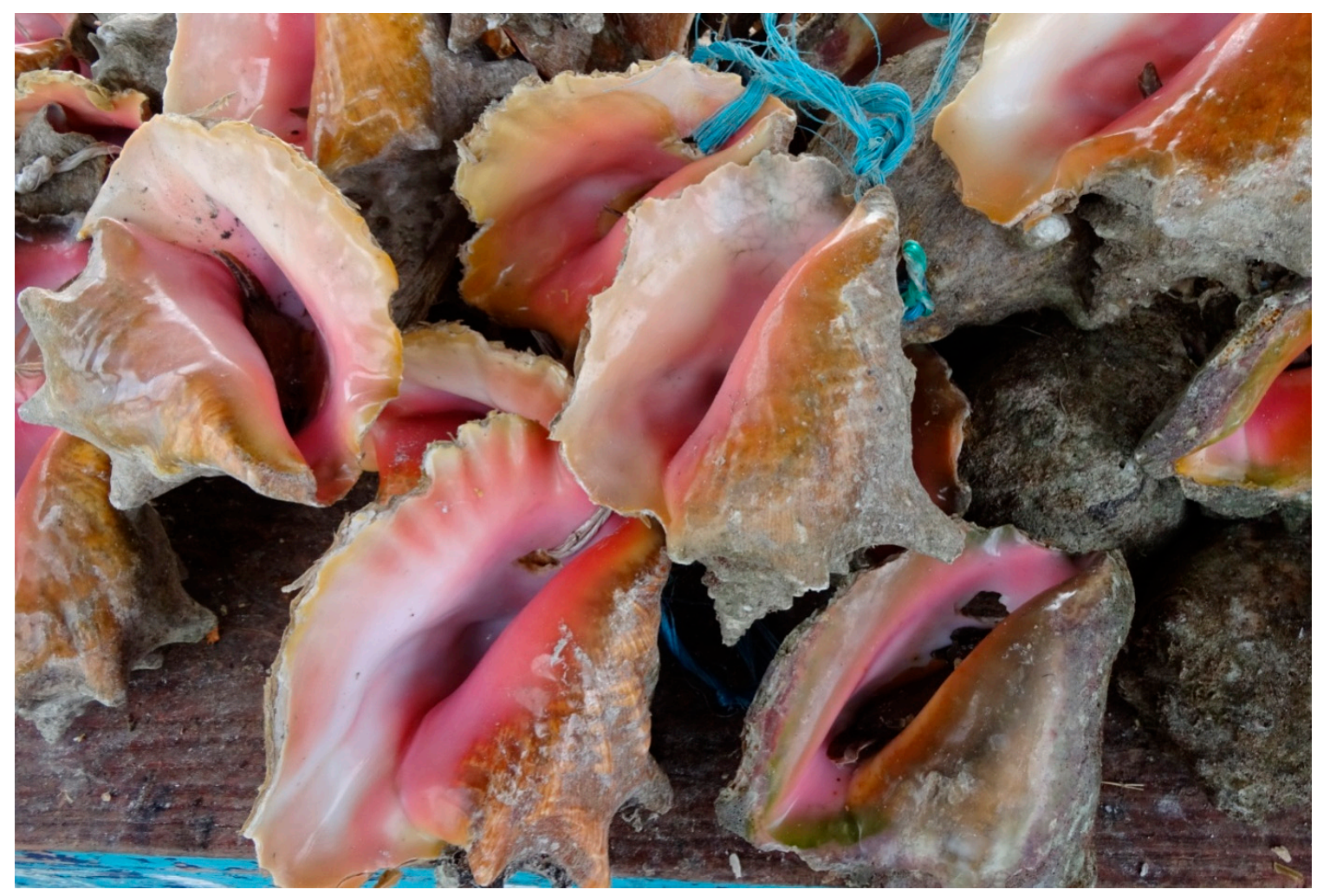

Figure 2. Fresh Conch in shells (Photo: Bomhauer-Beins, 2016).

\subsection{Conch from a Social System Perspective}

In this section, human-nature interactions between the Abaconian society and Conch are examined more closely from two different perspectives. First, we focus on the economic dimension and analyse how interactions between fisheries and marine resources led to a decline in Conch stocks. Secondly, we analyse the cultural embeddedness of Conch in the Abaconian society. Through these two lenses, we reveal how societal dynamics, interactions with the environment and patterns of behaviour shape social-ecological resilience in Abaco. 


\subsubsection{Economic Dimension}

Conch fishery is a crucial economic resource for The Bahamas: it relies on small boats which mainly fish in the shallow waters of the Little Bahama Bank and the Great Bahama Bank [26]. Conch is currently mainly harvested by free diving with hand collection, while traditionally, it was pulled out of the water by a hooked pole. More than the 60 percent of the annual total Conch meat is fished during the closed season for spiny lobster, from the 1st of April to the 31th of July. The meat is then mainly consumed locally, but some is also exported internationally, almost entirely to the United States. Recent data report that in 2015, around 401,838 pounds of Conch meat worth 2.3 million BSD were exported [27]. The export is regulated and controlled by an annual quota system and is subject to the CITES (Convention on International Trade in Endangered Species of Wild Fauna and Flora) guidelines [28].

To understand the current state of the Bahamian Conch fishery and its management, we analyse the historical dynamics and developments of Caribbean Conch fisheries through the adaptive cycle [11,29]. This heuristic model allows us to describe nonlinear dynamics and resilience in SES, to identify stressors or crucial events in the trajectory of the system and to point to possible trends and pathways [30]. Based on the fundamentals of complexity theory and the notions of social-ecological adaptability, panarchy highlights the role of context-based, hybrid and evolutionary trajectories in SES as well as of environmental knowledge and cultures [31]. The adaptive cycle comprises the four development phases of a complex adaptive system: growth and exploitation, conservation, collapse and release, and reorganization. The growth phase (r-phase) is characterised by rapid and extensive growth due to the fact that resources are readily available. This phase is accompanied by a high degree of resilience. The status of the system is still far away from its own threshold. The transition of the system to the next phase tends to be slow and gradual. The conservation phase (K-phase) is accompanied by a decrease of resilience. Interactions between system elements are increasing, and the system makes huge efforts for self-conservation. Resources are becoming increasingly scarce; growth is stagnating, making the system less flexible and more vulnerable towards external perturbations and shocks. The release phase $(\Omega$-phase) involves an abrupt and rapid change in the system structure. The transition to the reorganization phase ( $\alpha$-phase) is quick. In this chaotic phase, the system reorganizes itself by processes of innovation, experimentation and learning. This self-organisation leads to new forms of interactions between system elements, opening up new system trajectories. The system can remain in a roughly similar regime state (adaptation), or the system undergoes a radical change into a completely new regime that is fundamentally different from the former system (transformation). Then, the system enters into a new growth phase.

To apply the adaptive cycle to the Conch management, we could go back to pre-Columbian times when Conch fishing started, yet it is during the last five decades that Conch fisheries in the Wider Caribbean Region have undergone drastic changes, primarily due to a continuously overfishing of the Conch stocks. However, it wasn't until the 1970s that the Conch fishery became a commodity. This event marks the beginning of the growth phase (r-phase) of the adaptive cycle. Factors, such as an increasing national and international demand, a growing island population and an emerging mass tourism intensified the external pressures on the Conch stocks in the region [26,32]. This is reflected in the constantly increasing landing numbers since the 1980s in The Bahamas [28]. This trajectory of fisheries can be assigned to the conservation phase (K-phase) and initiated a slow and gradually downward trend in the Caribbean, which led to a collapse of several national Conch fisheries in the following decades ( $\Omega$-phase). In 1975 , commercial fishery in the Florida waters was closed due to a decline in the Conch population. The Bermuda Conch fishery was stopped in 1978 due to the low Conch density. In the mid-1980s, both commercial and recreational Conch fishing was banned in the Florida waters entirely, but since then, Conch stocks have never recovered and the ban still applies. In 1987, the overfishing has resulted in a collapse of the Conch fishery on Aruba [33]. In 1992, the CITES listed Conch as an endangered species. In response to this, The Bahamas introduced an export quota system in 1995 to control and regulate the export of Conch [26]. At the same time, studies documented a decline in 
the Conch stocks in Bahamian waters [34]. At the end of the 1990s, the Bahamian fishery department classified the national Conch stocks as healthy but pointed out that some primary fishing grounds around Abaco, Andros and the Berry Islands were overfished [35]. Other Caribbean island states, like Jamaica, stopped their national Conch fishery temporarily to prevent the stocks from collapsing [33] (see Figure 3).

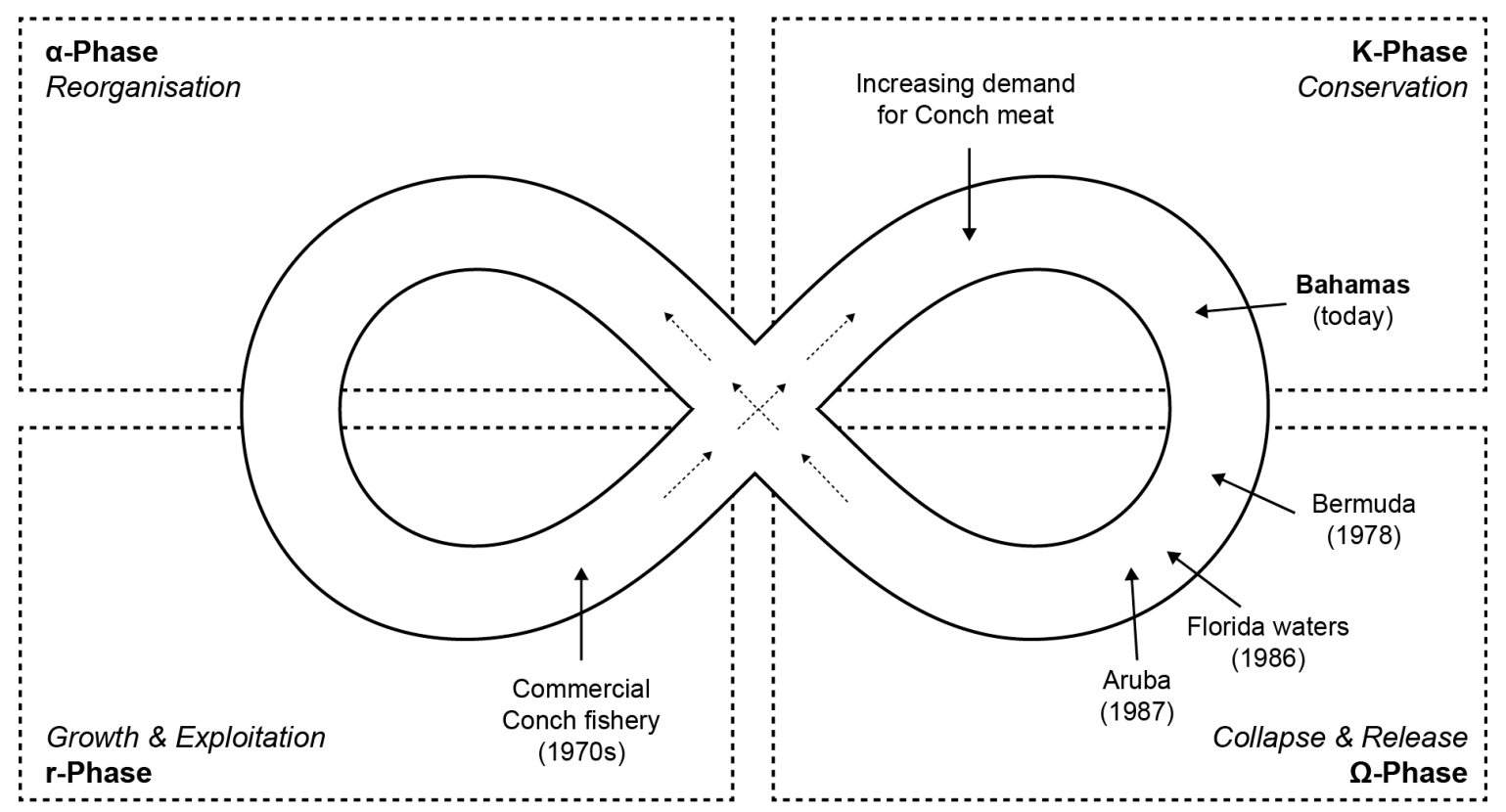

Figure 3. The trajectories of Conch fisheries in the Wider Caribbean Region.

Until today, Caribbean island states with an active Conch fishery have reacted very slowly with management measures, plans or strategies in respond to processes of change in Conch stocks. The control and regulation instruments implemented most commonly refer to a minimum size in terms of shell lip, shell length or weight, closed seasons, restrictions on the type of fishing gear or an export quota system. In The Bahamas, management measures are confined to an export quota system, to a restricted use of air compressors and, in a broader sense, by no-take marine protected areas (MPAs). A further important legislation is the lip restriction which states that to be legally fished, a Conch has to be a well-formed flared lip of its shell. Unfortunately, this legislation is ambiguous because the identification based on the shape of the shell lip is very subjective. Furthermore, recent studies, have confirmed that the legislation of a well-formed flared lip allows the legal harvest of juvenile Conch [36]. The governmental authorities, such as the Department of Marine Resources, the Royal Bahamas Defence Force, the Royal Bahamas Police Force and the Customs are responsible for enforcement issues but have only limited capacities.

The trajectories of Conch fisheries have shown that an ongoing overuse of the marine resource has led to an economic lock-in situation in The Bahamas and in the Wider Caribbean Region as well. Economic attractiveness of the resource along with factors like overfishing, illegal fishing and poaching coupled with ineffective/powerless regulations and a lack of law enforcement bring the Conch system closer to its threshold - both economically and ecologically. However, there is another factor which plays a decisive role in the game: the aspect of culture and its impact on the resilience of the Conch management.

\subsubsection{Cultural Dimension}

Conch is highly culturally embedded in Bahamian society. It has represented a staple protein food in the past and continues to do so today, especially for the people of the peripheral Out Islands. The fact that Conch is an essential icon of Bahamian identity is reflected in the presence of its beautiful 
shell in the national emblem which represents an important phase of identity formation. In fact, the emblem was implemented in 1971 during the transition period of the former British crown colony to the independence of the Bahamian archipelago state. The Conch is omnipresent in everyday island life. It is a national delicacy, deeply rooted in the traditional Bahamian cuisine in the form of Conch salad, Conch fritters or stewed Conch. In addition, it is used for several other cultural purposes, such as jewellery (Conch pearls), as a decoration item in many Bahamian front gardens (Conch shell) or as a traditional musical instrument (Conch horn). Diverse cultural events deal with Conch, such as Homecoming Festivals or Conch Cracking Festivals. Tourism also benefits from Conch: Many tourists are visiting The Bahamas for the experience of Conch food and fishing and to bring home the pink shimmering shell as a souvenir. The value of Conch for the Bahamian people is well-illustrated by an interview partner: "From a livelihood standpoint and from a touristic standpoint, it is one of our iconic species in The Bahamas. You can go to any other Caribbean island. They don't promote Conch like we do" (I15). Based on these finding and on existing literature on "cultural keystone species" $[37,38]$ and their roles in SES [14], the Conch can be seen as a keystone component in the Bahamian SES. In fact, such species have a high cultural value for individuals and society in addition to its importance for the ecosystem. A loss of Conch can have negative cascading effects for Bahamian culture and identity.

What is the significance of Conch for the Abaconian society? How do the local islanders interact with the marine resource? To answer these questions, we take a closer look-based on the data from the population survey-at the consumption of Conch, at fishing practices and at activities as well as at past experiences. In Abaco, the local consumption of Conch is very high. It is consumed by 92.8 percent of all respondents, of which 8.1 percent eat it less than once a month, 40.5 percent at least once a month, 37.8 percent at least once a week and surprisingly, 6.3 percent even on a daily basis. Only 7.2 percent of all respondents do not consume Conch due to health issues (e.g., diabetes) or for religious reasons (according to some religions, Conch is a scavenger, excluding any form of consumption) (see Figure 4).

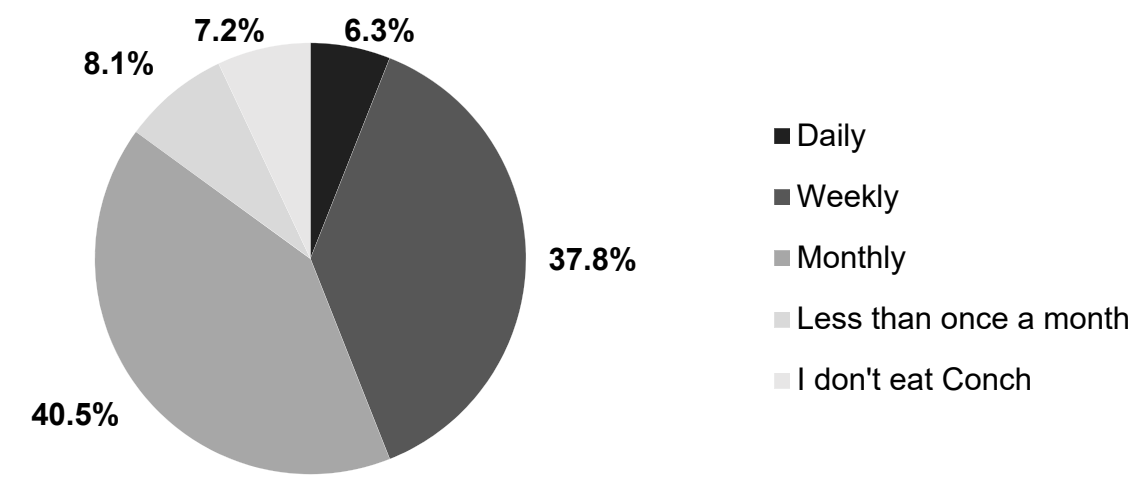

Figure 4. The consumption of Conch; "How often do you eat Conch?" (N=111).

The cultural significance of Conch for the Abaconian society can be also seen in the people's current fishing activities. Conch fishing (called conching) represents one of the most popular recreational activities of the islanders: "It is always part of a Sunday thing" (AS47). Nearly one third of all respondents do conching; however, the intensity and frequency varies greatly from weekly to monthly and up to only a few times a year. Some respondents deeply regretted that their daily work hinders them from fishing for Conch more often. Remarkably, almost all respondents have experienced Conch fishing during their lifetime. Many of them had their first contact with Conch in their earliest childhood: "I grew up with Conch. It is [a] fixture of our culture" (AS83). The individual memories are consistently positively connotated and indicate an emotional connection with the marine resource as the following answers of islanders illustrate:

"When I was a little girl of maybe eight years, my dad - he is [a] fisherman-brought Conch home. [... ] When the tide was low, we called it 'jump the banks'. We were looking for Conch and shells" (AS13) 
"One of my favourite memories is that we went out in a family boat; we dived for Conch, took it to the beach where my uncle cleaned it for us, and we made scorched Conch. We did it every summer in my childhood" (AS110)

There is a deep human-nature interaction between the islanders and the marine resources on the Bahamian Out Island Abaco present in everyday island life. For islanders, it is not only a stable food, a symbol of Bahamian identity or a recreational activity but also a relevant social function in Abaconians society. Conch is seen as integral part of The Bahamas and considered as bountiful and infinite. The experience of fishing and cooking connects people, not exclusively islanders to islanders but also islanders to tourists. The negative facet of such a close societal relationship with Conch is that it exerts a pressure on the marine resource and its stocks, potentially leading to a lock-in situation.

\subsection{The Management Process of a Vulnerable Marine Resource}

The previous sections have shown how from an ecological point of view, biological characteristics of Conch enhance its vulnerability to overfishing. In addition to that, economic factors (e.g., value, commodity and tourism) and cultural factors (e.g., food, events and activities) have negative impacts on the Conch stocks, contributing to a slow and gradual resource depletion at the local and national levels. This implies that not only the economic but also the cultural pressure might cause and intensify a potential collapse of the Conch population. Therefore, The Bahamas face the challenge of developing adaptive strategies for sustainable resource management that take into account both the ecological and social dimensions of Conch.

Since 2009, various Conch stock assessments have been conducted by the external NGO Community Conch in primary fishing grounds across the Bahamian archipelago-identifying Conch stocks as limited and under depletion. The results of these stock assessments coupled with current international research and the experience of the trajectories of Conch fisheries in other areas of the Caribbean triggered the foundation of the national campaign Conchservation in 2013. The campaign aims to proactively protect Conch before its overexploitation through research, citizen science and policy change and involves relevant stakeholders, including state and non-state agents (key campaign partners are Bahamas National Trust, Community Conch, Department of Marine Resources and The Nature Conservancy) on the local, national and international levels as well as in the private sector. The objectives are to increase public awareness about the current status of the Conch stocks, to develop adaptation strategies and to enhance a sustainable Conch fishery on The Bahamas. A key effort of the campaign partners is a call for change in legislation which currently allows the fishing of juvenile Conch. Despite certain support, a change in legislation has not been considered at the political level. Currently, there is no consensus among the key stakeholders as to which adaptation strategies could be suitable and which management measures should be implemented: the question of how to successfully and sustainably manage the marine resource is still open.

Current Conch management is trapped in a lock-in situation for multiple reasons, including conflicts of interests, communication problems, lack of trust and rigid patterns of behaviour at different levels. In particular, some stakeholders have different views, interests and ideas about the further management process. On one side, some campaign partners recognize the current body of knowledge as sufficient and argue for the need for a first step towards a more sustainable Conch management, even if it is not the final one. In contrast with this position, a few stakeholders see the proposed and discussed management tools as too limited and argue for a more comprehensive and complete sustainable resource management framework to adapt to the existing Conch problem. To do so, they call for more research and scientific knowledge to create long-term adaptation strategies. The trajectory of the campaign to date is viewed critically, which is why some stakeholders advocate a change of leadership in order to make the campaign more effective. On Abaco, for example, the campaign is hardly noticed by the islanders, partly due to an insufficient communication of information at the local level. Over the last decades, the lack of trust between fishermen and the government and its bodies has resulted in a disrupted communication relationship. Fishermen do not feel that 
they are understood and involved in the decision-making process, which can be seen in a partly defensive and indifferent behaviour towards new management measures. These social dynamics are more or less the result of the fact that culture is materialized in Conch, which makes a sustainable management challenging. According to some stakeholders, the cultural value of Conch in society represents a barrier to the management process. The Nature Conservancy states that "Conch here is so much part of cultural identity. [ ... ] We still have the cultural problem, the socio-economic problem, and that's a kind of chicken-and-egg [situation]" (I14). The Bahamas National Trust point out that "Conch is not seen as an environmental problem; it is seen as a cultural problem" (I9). As a demonstration of this, the suggested change in legislation has received no political attention either from the former government or from the current one. Political agents distance themselves from the decision-making in Conch management, framing Conch as too deeply embedded in the island's society to implement management measures. Only when islanders are fully aware of the-ecological-Conch problem and the public is ready to support the solutions will the central government implement adaptive strategies. Yet, the reason for their unwillingness to act and their hesitant behaviour can be seen in the concern that a lack of societal support could threaten their position of power. By doing so, culture-visible in the actions and behaviours of political agents-has obstructed and decelerated the management process, blocking urgently needed adaptation strategies. This situation triggers several feedback effects on the dynamic of the system as it increases the system's vulnerability and decreases the system's resilience and opportunities for adaptive pathways. It is foreseeable that without any adaptive management strategies, the Conch stocks will pass their critical ecological tipping point after which Conch can no longer reproduce. This potential abrupt collapse in the system's trajectory will likely generate cross-scale feedback effects in the economic, social and cultural systems, affecting the resilience of the entire SES.

Management strategies to achieve sustainable use of this crucial marine resource are hindered. On the one hand, political agents believe that their decisions will not be accepted by the public due to the lack of awareness coupled with the cultural value of Conch as a resource, commodity, diet and icon in the island's society. On the other hand, Bahamians do not want to abstain from eating Conch or from using the marine resource for commercial, recreational and touristic activities. Moreover, for many islanders, The Bahamas without Conch is hardly imaginable. Fishermen see no reason for further management measures. According to their knowledge/understanding, local Conch stocks are still in balance, abundant and infinite.

\section{Societal Potential for Adaptive Management}

In the previous section, we have shown that the current Conch management process is trapped in a lock-in situation, in part, due to the cultural values of Conch in the island's society. In the following section, we want to show the other side of the coin by arguing that culture is not only a barrier for adaptation strategies but also can be used as a positive impulse towards adaptive management and decision making. Based on the empirical study, we emphasize the existing cultural capacity of Abaconian society in terms of awareness and perception, protection and management tools.

\subsection{Cultural Capacity on Abaco}

The results from the population survey show that the Abaconian society has yet to perceive changes in local Conch stocks. One interviewed islander said: "Over the last years, Conch is declining very fast." (AS69). In contrast to the dominant political position, in our population survey, 60 percent of the respondents classify Conch as endangered, primarily due to overfishing, "People taking Conch again, again, again. They abuse them" (AS29), and illegal fishing, "Actually, people know the standard size of Conch, but some people taken undersized Conch" (AS56). Another 14.4 percent see Conch in a vulnerable situation in contrast with a 22.5 percent which assumed that the local stocks around Abaco are steady and in good conditions. Apparently, the permanent availability of Conch as a consumer good on the local market is clouding the problem picture of many islanders. Furthermore, respondents reported 
change in terms of size and market prices, attributing it to the fact that local fishermen have to go deeper and further to catch Conch: "The Conch is smaller now. You pay higher prices for less Conch" (AS3) (see Figure 5).

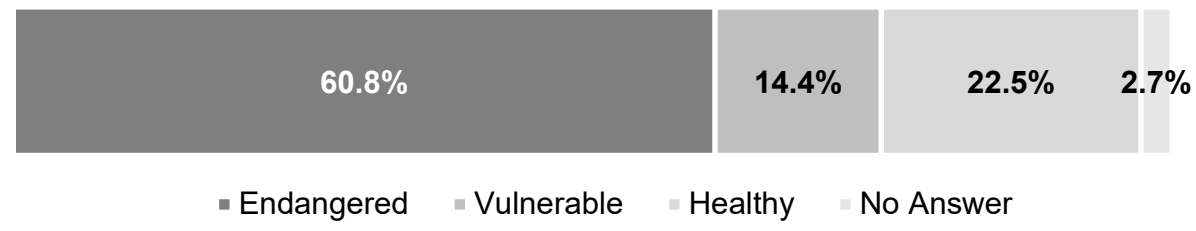

Figure 5. The Islander's perception of local Conch stocks: "How do you see the current situation of local Conch stocks?" ( $\mathrm{N}=111)$.

In contrast to the general understanding of politicians and stakeholders, the results from the survey show that the protection of Conch is perceived as a very important societal issue on Abaco. Respondents emphasized the cultural dimension-besides the ecological role for marine ecosystem dynamics and the economic value for many islanders-as one of the key reasons why Conch needs to be protected for future generations. Respondents mentioned the social relevance of Conch in the daily life: "It is a big cultural thing. It is linked to our society" (AS3) and "Conch is such an important part of the Bahamian culture. It is part of the Bahamian experience, for locals and visitors as well" (AS110). Both the perception of the issue of Conch depletion and a general understanding of resource protection have fostered the island societies' preference for urgent Conch management actions as reflected by a 92.8 percent of respondents which called for further management measures to protect the Conch stocks more adequately. For example, a closed season on Conch is perceived as an effective management tool, based on the observed positive impacts of the present closed seasons on other heavily fished marine species, such as spiny lobster and Nassau grouper. A respondent said that "We need further regulations to protect Conch, maybe a [closed] season on Conch, to protect Conch" (AS3). Other preferred management measures are a general export ban and a stricter enforcement of fishery regulations by government bodies. In terms of the societal potential, the most interesting aspect is the allocation of responsibility to the government and its bodies. "Yes, they [the government] should close it. We need a [closed] season on Conch" (AS13). Some respondents explicitly criticized the government's inactivity and passivity, as one islander said, "They put a [closed] season on lobster. They put a [closed] season on grouper. Why we don't have a [closed] season on Conch?" (AS72). In contrast to the dominant political hesitation to get active, there is a general understanding that action is needed to protect the society's icon from overexploitation. However, actions are expected almost exclusively from the government and its bodies. The Abaconians show passive and sluggish behaviour in view of the relevance of needed actions in Conch management on the local and national levels. This is particularly noteworthy given that the government is perceived by islanders as corrupt, distrustful and power-obsessed.

\subsection{Adaptive Pathways for a Sustainable Resource Management}

The cultural significance of Conch in Abaco's society, however, also opens a "window of opportunity" which can be used to handle the management lock-in situation and to avoid the system transition in the release phase ( $\Omega$-phase). How can culture be activated or stimulated to enhance social-ecological resilience? This section provides three different "adaptive pathways" [39,40], which illustrate how the cultural capacity of the island's society can be used towards adaptive strategies and resilient sustainable development in Bahamian Conch management.

A first pathway in Conch management emphasizes the role of bridging organisations. Such institutions offer an opportunity to improve and/or trigger decision-making processes associated with knowledge coproduction in the area of environmental and resource management by spanning the government-public interface [41]. Bridging organisations can be seen as an institutional mechanism to link and facilitate interactions among divergent interest groups as well as types of knowledge [42-44]. 
According to Berkes (2009: 1695), an important benefit of bridging organisations is to "provide an arena for knowledge coproduction, trust building, sense making, learning, vertical and horizontal collaboration, and conflict resolution" [43]. In the context of Conch management, non-governmental agents of the national campaign Conchservation can act as bridging organizations, forwarding the societal claims to the politicians to support them in a participatory decision-making process. In particular, the Bahamas National Trust (BNT) seems suitable, as the NGO already has the mandate to advise the government on environmental issues. It is generally known that a wide societal support can benefit decisions and can activate the willingness for change at the political level. A negotiation process between the government and island society initiated by bridging organizations has the potential to move from the locked $\mathrm{K}$-phase of the adaptive cycle to the reorganization phase ( $\alpha$-phase), increasing the social-ecological resilience and avoiding system collapse.

Secondly, local participation can open a new pathway in Conch management. On Abaco, the two communities of Grand Cay and Cherokee Sound are particularly proactive in resource management. The islanders call for marine-protected areas and for autonomous management of the Conch habitats and nursery grounds on their doorstep. The sharing of power and responsibility-central characteristics of adaptive co-management [45] — between resource managers and local people can lead to a win-win situation in Conch management. In fact, such a community-based participation in the management of marine-protected areas can reduce the pressure on the already limited capacities of the monitoring and control of responsible authorities, can enhance community leadership and can build trust between interest groups at different levels. If it works, it can have a positive cross-scale impact by inspiring other communities locally and nationally to do it in the same way.

A third pathway refers to the power of individuals and society. Local people can raise their voice through a cultural movement defending their interests and advocating for ideas of sustainable Conch management. Such a bottom-up movement can exert the societal pressure on the government and can cause or force decisions to be taken. However, this pathway is confronted by some challenges, primarily due to the passive and cumbrous behaviour of Abaconians. Complementary to this, the power relationship between islanders and the government plays a critical role. From the islander's perspective, the government is characterised by corruption and power struggles. Over the past decades, the trust in the central government has eroded and Abaconians seem tired of politics and participative decision-making processes. Without the active willingness of the island's society to change the dynamics and trajectories of the system, however, the current situation in Conch management becomes increasingly intractable. The consequent abrupt transition to the $\Omega$-phase seems indisputable with negative cascading feedback effects, primarily for the marine ecosystem but also socially, culturally and economically.

\section{An Innovative Understanding of SES, Resilience and Culture}

A social-ecological resilience perspective analyses nonlinear dynamics, cross-scale interactions and feedbacks. Abaco gives an instructive example of the panarchy of societal reaction to natural resource depletion-a decline in Conch stocks on the local as well as national levels. With this approach, we addressed two prominent aspects of the current discussion on the SES and resilience theory. The first aspect is the interaction of the social and ecological system; the second one is the crucial role that culture plays in this interaction.

As discussed above, the appropriateness of integrating ecological and social systems has been questioned due to their different characteristics and to different paradigms traditionally used to analyse them. In our work, we show that this integration is not only possible but also necessary to understand the feedbacks mechanisms that mutually occur between social and ecological systems and the associated pathways of SES. In the case of Conch in Abaco (Bahamas), the interrelation and interactions between the two interlinked subsystems are exceptionally powerful and evident. This is due to the nature of the object at stake: Conch. Conch is not just a marine creature. It is one of the most important economic marine resources of The Bahamas and, as a keystone component, it is part of the 
everyday culture at the individual social level: It is a materialization of culture. On the one hand and at this scale, the stressor is the decrease in Conch stocks and being resilient to it would mean bringing the Conch population in balance. If solutions such as sustainable resource management can be an option to foster resilience in the marine ecosystem, they might also have some negative feedback effects for other subsystems or system elements, like the fishermen community. This highlights, once more, the relevance of the question "Resilience for whom?" when identifying possible adaptive pathways [9]. On the other hand, it is crucial to understand the interlinkages between different systems: Radical change in a faster system at a lower scale can foster the resilience of a slower system at higher scales [46]. In the case of Conch, on the one hand, a collapse of the ecological system (Conch stocks) can provoke cascading effects within the social system in terms of cultural and social disruptions and economic loss. On the other hand, we identified a further, subtler yet relevant aspect in the relation between the social and ecological system of Conch. Namely, the fact that the biological characteristics of Conch (spawning season, movement and habitat) facilitated its overfishing and possibly the spread of its use and of the culture activities related to that. Based on this observation, it is clear that the two systems-social and ecological-are interlinked by feedback processes and are inseparable. Examining their nonlinear dynamics is the basis for identifying the multiple causes and consequences of a stressor, identifying viable pathways and, more broadly, understanding the resilience process.

The second, crucial contribution of this study is the analysis of the role of culture in shaping social-ecological resilience. The absence of culture in resilience thinking has been pointed out by a number of authors $[16,18]$. We reacted to this call by bringing to light how societal dynamics-shaped by culture-influence resilience processes in terms of the identification of pathways, the allocation of responsibility and visions of the future. By looking at resilience from a cultural perspective, we revealed how aspects such as conflicts of interest, a lack of trust and communication problems lead to the current lock-in situation in Conch management. In a second step, we revealed how cultural features such as values, patterns of interaction and a close relation with the marine resource can be starting points to identify and embark on resilient pathways.

Our study reveals that there is no disagreement in the island's society in terms of "Resilience to what?" Different stakeholders and decision makers are addressing the recognizable resource depletion and point to the maintenance of Conch stocks in the Bahamian archipelago for its cultural, economic and social relevance, yet there is no agreement on how to achieve it and who should be responsible for it, and this is exactly where culture plays its role: in its power to obstruct or decelerate management approaches or, alternatively, in its potential to open new adaptive pathways. Everyday human-nature interactions as well as islanders' emotional attachment to the marine resource, the societal dynamics, social memory and past pathways shaped the trajectory of Conch to a lock-in situation. Only the future will show if these cultural dynamics of the island's society can be mobilized to overcome the lock-in situation currently found in the Abaconian SES and to support a sustainable development pathway for the islands.

Author Contributions: L.B.-B. and C.d.G. conceived the main idea of the manuscript under the supervision of B.M.W.R.; L.B.-B. did the related empirical analysis; All three authors jointly wrote the final manuscript and did paper revisions.

Funding: The authors thank the German Research Foundation (Deutsche Forschungsgemeinschaft, DFG) for funding the research project: "Adaptability of social-ecological systems. Environmental knowledge, learning and governance on small islands from a complexity theory perspective." (project number: 269338475).

Acknowledgments: We would like to thank all Bahamian people, who contributed to the success of this study through their knowledge and wisdom in their distinctive friendly and open manner. The authors are grateful to three anonymous reviewers for their constructive comments and suggestions.

Conflicts of Interest: The authors declare no conflict of interest. 


\section{References}

1. Walker, B.; Salt, D. The system rules: Creating a mind space for resilience thinking. In Resilience Thinking Sustaining Ecosystems and People in a Changing World; Walker, B., Salt, D., Eds.; Island Press: Washington, DC, USA, 2006; pp. 28-38, ISBN 978-1-5972-6093-0.

2. Beichler, S.; Hasibovic, S.; Davidse, B.; Deppisch, S. The role played by social-ecological resilience as a method of integration in interdisciplinary research. Ecol. Soc. 2014, 19, 3. [CrossRef]

3. Deppisch, S.; Hasibovic, S. Social-ecological resilience thinking as a bridging concept in transdisciplinary research on climate-change adaptation. Nat. Hazards 2013, 67, 117-127. [CrossRef]

4. Baggio, J.; Brown, K.; Hellebrandt, D. Boundary object or bridging concept? Acitation network analysis of resilience. Ecol. Soc. 2015, 20, 2. [CrossRef]

5. Biesbroek, R.; Dupuis, J.; Wellstead, A. Explaining through causal mechanisms: Resilience and governance of social-ecological systems. Curr. Opin. Environ. Sustain. 2017, 28, 64-70. [CrossRef]

6. Hahn, T.; Nykvist, B. Are adaptations self-organized, autonomous, and harmonious? Assessing the social-ecological resilience literature. Ecol. Soc. 2017, 22, 1. [CrossRef]

7. Arora-Jonsson, S. Does resilience have a culture? Ecocultures and the politics of knowledge production. Ecol. Econ. 2016, 121, 98-107. [CrossRef]

8. Cutter, S.L. Resilience to What? Resilience for Whom? Geogr. J. 2016, 182, 110-113. [CrossRef]

9. Holling, C.S. Resilience and stability of ecological systems. Annu. Rev. Ecol. Evol. Syst. 1973, 4, 1-23. [CrossRef]

10. Holling, C.S. The resilience of terrestrial ecosystems. Local surprise and global change. In Sustainable Development of the Biosphere; Clark, W.C., Munn, R.E., Eds.; Cambridge University Press: Cambridge, UK, 1986; pp. 292-317, ISBN 978-0-5213-2369-7.

11. Holdschlag, A.; Ratter, B.M.W. Multiscale system dynamics of humans and nature in The Bahamas. Pertubation, knowledge, panarchy and resilience. Sustain. Sci. 2013, 8, 407-421. [CrossRef]

12. Davoudi, S. Resilience: A bridging concept or a dead end? Plan. Theory Pract. 2012, 13, 299-333. [CrossRef]

13. Davidson, D. The applicability of the concept of resilience to social systems: Some sources of optimism and nagging doubts. Soc. Nat. Resour. 2010, 23, 1135-1149. [CrossRef]

14. Winter, K.B.; Lincoln, N.K.; Berkes, F. The Social-Ecological Keystone Concept: A metaphor for understanding the structure, function, and resilience of a biocultural system. Sustainability 2018, 10, 3294. [CrossRef]

15. Stone-Jovicich, S. Probing the interfaces between the social sciences and social-ecological resilience: Insights from integrative and hybrid perspectives in the social sciences. Ecol. Soc. 2015, 20, 25. [CrossRef]

16. Cote, M.; Nightingale, A.J. Resilience thinking meets social theory: Situating social change in socio-ecological systems (SES) research. Prog. Hum. Geogr. 2012, 36, 475-489. [CrossRef]

17. Ratter, B.M.W. Complexity and Emergence-Key concepts in non-linear dynamic systems. In Human-Nature Interactions in the Anthropocene: Potentials of Social-Ecological Systems Analysis; Glaser, M., Krause, G., Ratter, B.M.W., Welp, M., Eds.; Routledge: New York, NY, USA, 2012; pp. 90-104, ISBN 978-0-4155-1000-4.

18. Lade, S.J.; Niiranen, S.; Hentati-Sundberg, J.; Blenckner, T.; Boonstra, W.J.; Orach, K.; Quaas, M.F.; Österblom, H.; Schlüter, M. An empirical model of the Baltic Sea reveals the importance of social dynamics for ecological regime shifts. Proc. Natl. Acad. Sci. USA 2015, 112, 11120-11125. [CrossRef] [PubMed]

19. Randall, J.E. Contributions to the biology of the queen conch, Strombus gigas. Bull. Mar. Sci. 1964, 14, 246-295.

20. Stoner, A.W. What constitutes essential nursery habitat for a marine species? A case study of habitat form and function for queen conch. Mar. Ecol. Prog. Ser. 2003, 257, 275-289. [CrossRef]

21. Stoner, A.W.; Sandt, V.J.; Boidron-Metairon, I.F. Seasonality of reproductive activity and abundance of veligers in queen conch, Strombus gigas. Fish. Bull. 1992, 90, 161-170.

22. Stoner, A.; Davis, M.; Booker, C. Surveys of Queen Conch Population and Reproductive Biology at Sandy Point and More's Island, Bight of Abaco, The Bahamas. 2012. Available online: www.communityconch.org (accessed on 24 July 2018).

23. Stoner, A.; Davis, M.; Booker, C. Surveys of Queen Conch Populations and Reproductive Biology on the Little Bahama Bank, The Bahamas. 2014. Available online: www.communityconch.org (accessed on 24 July 2018). 
24. Stoner, A.W.; Davis, M.H.; Kough, A.S. Relationships between Fishing Pressure and Stock Structure in Queen Conch (Lobatus gigas) Populations: Synthesis of Long-Term Surveys and Evidence for Overfishing in The Bahamas. Rev. Fish. Sci. Aquac. 2018. [CrossRef]

25. Stoner, A.W.; Ray-Culp, M. Evidence for Allee effects in an over-harvested marine gastropod: Density-dependent mating and egg production. Mar. Ecol. Prog. Ser. 2000, 202, 297-302. [CrossRef]

26. Theile, S. Queen Conch Fisheries and Their Management in the Caribbean. Available online: http:/ / www2. cedarcrest.edu/academic/bio/jcigliano/MFEC/traffic_europe_report.pdf (accessed on 8 August 2018).

27. FAO. Fisheries and Aquaculture in The Bahamas. A Review; Food and Agriculture Organization and Department of Marine Resources: Nassau, Bahamas, 2016. Available online: https://www.bahamas.gov.bs/wps/ wcm/connect/e1d636dd-1a9b-4661-9e38-ba9bf546a534/FINAL+Bahamas+Fisheries+\%26+Aquaculture+ Sector+Review+17Nov16.pdf?MOD=AJPERES (accessed on 10 August 2018).

28. Gittens, L.; Braynen, M.T. Bahamas National Report-CFMC/OSPESCA/WECAFC/CFRM Working Group on Queen Conch; Department of Marine Resources: Nassau, The Bahamas, 2012.

29. Gunderson, L.H.; Holling, C.S. Panarchy. Understanding Transformations in Human and Natural Systems; Island Press: Washington, DC, USA, 2002.

30. Abel, N.; Cumming, D.H.M.; Anderies, J.M. Collapse and Reorganization in Social-Ecological Systems. Question, Some Ideas, and Policy Implications. Ecol. Soc. 2006, 11, 17. [CrossRef]

31. Holdschlag, A.; Ratter, B.M.W. Caribbean Island States in a Social-Ecological Panarchy? Complexity Theory, Adaptability and Environmental Knowledge Systems. Anthropocene 2016, 13, 80-93. [CrossRef]

32. Appeldoorn, R.S.; Castro Gonzalez, E.; Glazer, R.; Prada, M. Applying EBM to queen conch fisheries in the Caribbean. In Towards Marine Ecosystem-Based Management in the Caribbean; Fanning, L., Mahon, R., McConney, P., Eds.; Amsterdam University Press: Amsterdam, The Netherlands, 2011; pp. 177-186, ISBN 978-9-0896-4242-4.

33. NOAA. Queen Conch, Strombus Gigas (Linnaeus 1758). Status Report; 2012. Available online: http:/ / www. cio.noaa.gov/services_programs/prplans/pdfs/ID236_Queen_Conch_Peer_Review_Report.pdf (accessed on 4 August 2018).

34. Stoner, A.W.; Ray, M. Queen conch, Strombus gigas, in fished and unfished locations of the Bahamas: Effects of a marine fishery reserve on adults, juveniles, and larval production. Fish. Bull. 1996, 94, 551-565.

35. CFMC. Queen Conch Stock Assessment and Management Workshop. Belize City, Belize. 1999. Available online: http:/ / caribbeanfmc.com/reports-sci-docs/BelizeConchWGReportFinal.PDF (accessed on 4 August 2018).

36. Mueller, K.; Stoner, A.W. Proxy measures for queen conch (Strombus gigas Linné, 1758). Age and maturity: Relationships between shell lip thickness and Operculum dimensions. J. Shellfish Res. 2013, 32, 739-744. [CrossRef]

37. Garibaldi, A.; Turner, A. Cultural keystone species: Implications for ecological conservation and restoration. Ecol. Soc. 2004, 9, 3. [CrossRef]

38. Brosi, B.J.; Balick, M.; Wolkow, R.; Lee, R.; Kostka, M.; Raynor, W.; Gallen, R.; Raynor, A.; Lee, L.D. Quantifying cultural erosion and its relationship to biodiversity conservation: Canoe-making knowledge in Pohnpei, Micronesia. Conserv. Biol. 2007, 21, 875-879. [CrossRef]

39. Wise, R.M.; Fazey, I.; Stafford Smith, M.; Park, S.E.; Eakin, H.C.; Archer Van Garderen, E.R.M.; Campbell, B. Reconceptualising adaptation to climate change as part of pathways of change and response. Glob. Environ. Chang. 2014, 28, 325-336. [CrossRef]

40. Abel, N.; Wise, R.M.; Colloff, M.J.; Walker, B.H.; Butler, J.R.A.; Ryan, P.; Norman, C.; Langston, A.; Anderies, J.M.; Gorddard, R.; et al. Building resilient pathways to transformation when 'no one is in charge': Insights from Australia's Murray-Darling Basin. Ecol. Soc. 2016, 21, 23. [CrossRef]

41. Armitage, D.; Berkes, F.; Dale, A.; Kocho-Schellenberg, E.; Patton, E. Co-management and the co-production of knowledge: Learning to adapt in Canada's Arctic. Glob. Environ. Chang. 2011, 21, 995-1004. [CrossRef]

42. Folke, C.; Hahn, T.; Olsson, P.; Norberg, J. Adaptive governance of social-ecological systems. Annu. Rev. Environ. Resour. 2005, 30, 441-473. [CrossRef]

43. Berkes, F. Evolution of co-management: Role of knowledge generation, bridging organizations and social learning. J. Environ. Manag. 2009, 90, 1692-1702. [CrossRef] [PubMed]

44. Kowalski, A.A.; Jenkins, L.D. The role of bridging organizations in environmental management: Examining social networks in working groups. Ecol. Soc. 2015, 20, 16. [CrossRef] 
45. Olsson, P.; Folke, C.; Berkes, F. Adaptive co-management for building resilience in social-ecological systems. Environ. Manag. 2004, 34, 75-90. [CrossRef] [PubMed]

46. Folke, C.; Carpenter, S.R.; Walker, B.; Scheffer, M.; Chapin, T.; Rockström, J. Resilience thinking. Integrating Resilience, Adaptability and Transformability. Ecol. Soc. 2010, 15, 20. [CrossRef]

(C) 2019 by the authors. Licensee MDPI, Basel, Switzerland. This article is an open access article distributed under the terms and conditions of the Creative Commons Attribution (CC BY) license (http://creativecommons.org/licenses/by/4.0/). 